\title{
Purchase of a handgun was associated with an increased risk of suicide or death by homicide
}

Cummings P, Koepsell TD, Grossman DC, et al. The association between the purchase of a handgun and homicide or suicide. Am J Public Health 1997 Jun;87:974-8.

\section{Objective}

To determine if an association exists between purchase of a handgun from a licensed dealer and the risk of death from suicide or homicide.

\section{Design}

Case control study.

\section{Setting}

A large health maintenance organisation in Washington State, USA.

\section{Participants}

353 suicide victims and 117 homicide victims who died between 1980 and 1992 were included as case patients. 5 control participants were sought for each case patient matched for age, sex, and area of residence and this was achieved for $96.3 \%$ of case patients. Case patients were identified from the health group's membership records and state death certificates.

\section{Assessment of risk factors}

Handgun purchase information was obtained from the Department of Licensing. 3 categories were identified: family purchase (purchase by the study participant or any family member); personal purchase (purchase by the study participant); and family member purchase (purchase by any family member but not the study participant).

\section{Main outcome measures}

Adjusted relative risk of death by suicide or homicide.

\begin{abstract}
Main results
After adjustment for age, sex, area of residence, and date of case patient's death, the relative risk (RR) of suicide after a family handgun purchase was 1.9 (95\% CI 1.4 to 2.5$)$. The median time between the first purchase of a handgun by the victim or any family member and suicide using a gun was 10.7 years (range 11 days to 52.5 years). The RR of suicide given a family handgun purchase was greatest within the first year after purchase and remained increased after 5 years $(<1$ y since family purchase, RR 5.7, CI 2.4 to $13.5 ; 1$ to 4 y, RR 1.7 , CI 0.8 to $3.4 ; \geqslant 5$ y, RR 1.7, CI 1.3 to 2.3 ). The RR of suicide did not vary with maximum calibre of family handgun purchase. The RR of death by homicide for those with a family handgun purchase was 2.2 (CI 1.3 to 3.7). The median time between the first purchase of a family handgun and death by homicide with a gun was 11.3 years (range 5.1 to 21.9 ). The RR of death by homicide did not vary by time since purchase or by calibre of gun. The RR of death by homicide increased as the number of handgun purchases increased (1 family purchase, RR 1.1 CI 0.5 to 2.5 ; 2 purchases, RR 2.1, CI 0.8 to 5.2; $\geqslant 3$ purchases, RR 6.2, CI 2.4 to 15.6).
\end{abstract}

\section{Conclusion}

Purchase of a handgun was associated with an increased risk of suicide or death by homicide.

Source of funding: Group Health Foundation

For article reprint: Dr P Cummings, Harborview Injury Prevention and Research Center, Box 359960, 325 Ninth Avenue, Seattle, WA 98104-2499, USA. Fax +1 2065211562.

\section{Commentary}

To place this study in context for readers in other countries, it is important to emphasise that in the United States guns for personal use are easily available and gun control is a hotly debated political and social issue. A body of opinion exists supporting the belief that widespread personal ownership of firearms prevents injury or death more often than it causes harm. This may surprise readers in the UK, which has strict gun controls and where the overwhelming public view that guns are dangerous has recently led to legislation which effectively eradicates private ownership of handguns. This differs from the United States where guns are found in approximately half of all homes. ${ }^{1}$

It is also instructive to look at other differences between the 2 countries: in 1994 the homicide rate in the United States was 96 per million population; in England and Wales the rate was 12.4 per million. In the United States guns are used in about $72 \%$ of homicides ${ }^{2}$; in England and Wales the figure is $10 \%{ }^{3}$ Therefore, in the
United States in 1994 about 18000 citizens were shot dead; in England and Wales the number was 66 .

What are the implications of this study for the health of the population of the United States? If the RRs reported by Cummings $e t$ al are valid, the population attributable risk (population attributable risk is an estimate of the proportion of all cases, in this case suicide or homicide deaths, which would be prevented if the exposure, in this case handgun purchase, was absent) attached to family handgun purchase for suicide is about $12 \%$ and for death by homicide it is approximately $12.5 \%$. Assuming that the sample used by Cummings et al is reasonably representative of the United States, this means that the removal of exposure to family purchased handguns could prevent about 3700 suicides and 3000 homicides each year. The authors do not give data on how many suicides and homicides in the study were shot using their own or their family's weapons, and this omission is perhaps the main criticism of this otherwise important contribution to research which supports the hypothesis that guns are dangerous. Caroline Bradley, MB, BS, MRCP, MRCPsych, DFP Warneford Hospital Headington, Oxford, UK

1 Kellerman AL. Comment: gunsmokechanging public attitudes toward smoking and firearms. Am J Public Health 1997;87:910-3.

2 Singh GK, Kochanek KD, MacDorman MF. Advance report of final mortality statistics, 1994. Month Vital Stat Rep 1996;45:suppl.

3 Criminal Statistics England and Wales 1995. London: The Stationery Office Limited.

\section{Author's response}

If available, information about the gun used in each shooting would have been useful. Interpreting this information, however, might not be straightforward. Imagine that 2 men argue. Mr Jones brandishes his handgun. Mr Smith then draws a gun and kills Mr Jones. Mr Jones' gun may have contributed to his death although it was not the gun with which he was shot.

Peter Cummings, MD, MPH 